\title{
Characterization of Current Transportation Challenges in the Federal Capital Territory, Nigeria
}

\author{
Sumaila Abdul Ganiyu Femi ${ }^{1}$ \\ ${ }^{1}$ Department of Transport Management Technology, Federal University of Technology, Minna, Nigeria \\ Correspondence: Sumaila Abdul Ganiyu Femi, Department of Transport Management Technology, Federal \\ University of Technology, Minna, Nigeria. E-mail: drsumaila56@yahoo.com
}

Received: October 21, 2012 Accepted: November 24, 2012 Online Published: November 30, 2012

doi:10.5539/jsd.v5n12p117 URL: http://dx.doi.org/10.5539/jsd.v5n12p117

\begin{abstract}
This study is concerned with current and emerging transportation problems in Nigeria's Federal Capital Territory. The major objective is to identify and characterize the main challenges confronting mobility in the capital territory and propose a viable institutional framework for effective transportation management in FCT. The study is based on information arising from field auditing and evaluation of Abuja Master Plan. Information on extent of implementation of the transportation plan, level of distortion to and deviations from the plan, observable anomalies in traffic management and bottlenecks to traffic flow, provision and conditions of transport furniture and other relevant information from FCDA published materials provided the required data for the study. The study identifies the current challenges to include non-development of transit ways to major activity centres, emergence of illegal bus stations, poor parking facilities, absence of pedestrian walkways, widespread use of low-occupancy vehicles for public transport, city-wide traffic congestion, growth of squatter and shanty settlements, safety and administrative challenges. The study notes that the challenges are due to the inefficiency of the present institutional mechanism for managing transport in the city. Based on this premise, the study recommends the establishment of Abuja Area Transportation Authority as a sustainable transportation management strategy for FCT.
\end{abstract}

Keywords: transport infrastructure, mobility, traffic congestion, mass transit, pedestrian walkway, interchange point

\section{Introduction}

Transportation is no doubt an indispensible catalyst for activating and stimulating the tempo of economic, social, political and strategic development in any society. Thus, effective and efficient functioning of urban centres depends on the provision of basic infrastructures one of the most important being transport. This implies that transport infrastructure has to be rationally developed to ensure that movement of people and goods takes place speedily, economically, safely, comfortably and in an environmentally-friendly manner (Sumaila, 2012).

As compliments, there must also be strategic transport infrastructural development to enable all available transport modes to be properly harnessed, stream-lined and integrated for socio-economic and defence purposes (Gbujie, 2003). But whether transport infrastructure is rationally or strategically developed, the benefits could only be optimized if it promotes a sustainable transport system that guarantees safe, reliable, efficient and environmentally-friendly movement of people and goods. This is practically important for new cities like Abuja. If they must overcome the congestion monster that bedevils urban centres globally i.e. congestions of people, houses and traffic (Ogunsanya, 1995). These problems constituted the nation's experience in Lagos to the extent that their magnitude affected the national psyche. Consequently, in 1975, the Federal Government of Nigeria decided to relocate the federal capital to Abuja. It was expected that the relocation exercise would eliminate all the problems associated with transportation in Lagos. But the development of the capital territory in the last thirty years has created its own transportation challenges which require robust management strategies to handle. It is against this background that this paper identifies and characterises the current challenges confronting mobility in the Federal Capital Territory and proposes a viable institutional framework for effective transportation management in the territory. 


\section{Facts about FCT}

The Federal Capital Territory (FCT) was created as the nation's major response to the problems of Lagos. It was established through the instrumentality of Decree No 6 of $5^{\text {th }}$ February, 1976. It is geographically located at the centre of the country just above the hot and humid lowlands of Niger-Benue, but below the drier part of the country lying to the north. It is therefore easily accessible from all parts of the country. It shares boundaries in the north with Kaduna state, west with Niger state, south- west with Kogi State, east and south-east with Nassarawa state (see Figure 1a). The FCT covers an area of $8000 \mathrm{Sq} \mathrm{km}$ which is larger in landmass than seven states in the country. (Anambra, Ekiti, Lagos, Imo, Akwa Ibom, Ebonyi and Abia) and compares in size with four others (Rivers Enugu, Ondo and Osun) (Gbujie, 2008). Abuja, easily identifiable by Aso Hills is on the Gwagwa plains placed in the eastern gradient of the territory and it is about $3 \%(250 \mathrm{sq} \mathrm{km})$ of the total land area of the Federal Capital Territory (see Figure 1b). The remaining $97 \%$ of the land area is meant for the development of satellite towns (IPA, 1979).

The design, construction and management of the territory were vested in Federal Capital.

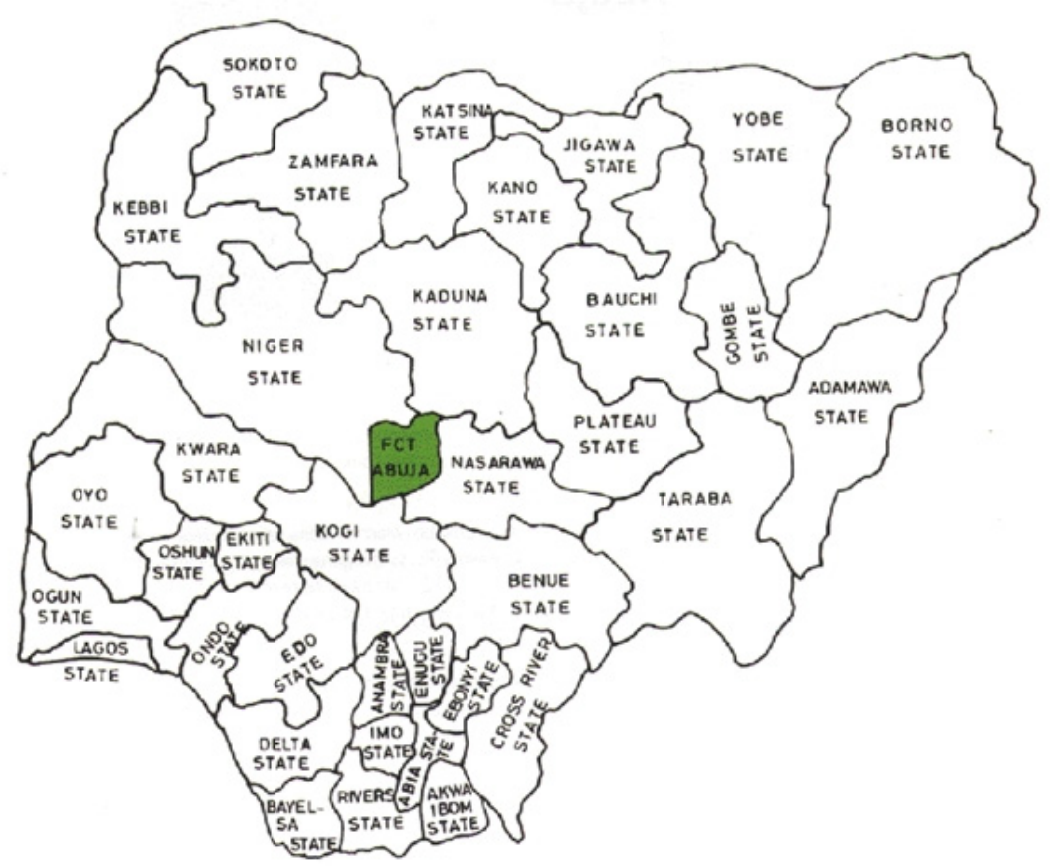

Figure 1a. Nigeria map showing the Federal Capital Territory

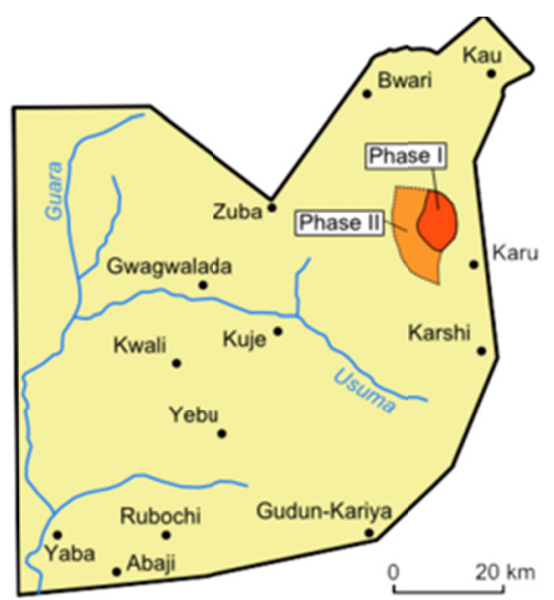

Figure 1b. The Federal Capital Territory 
Development Authority (FCDA) which commenced physical development in 1981 . By $12^{\text {th }}$ December 1991 , the seat of government moved from Lagos to Abuja.

In 1985, the delegation of Presidential powers for the FCT and that of the FCDA Board to the Honourable Minister of FCT brought the FCDA under the direct supervision of the Ministry of Federal Capital. While the Ministry is structured to provide the policy framework for both the physical, socio-economic and political development of the territory, the FCDA functions as its implementing agency responsible for the provision of infrastructural facilities, management and control of all urban services including transportation.

Presently, the FCT is made up of six Area Councils responsible for local administration and provision of basic social services. It had an official population of 1.4 Million in 2006 (see Table 1), but given the daily influx of people into the territory, the population today could be well over 8 million people.

Table 1. FCT and its Area Councils

\begin{tabular}{lll}
\hline Area Councils & Headquaters & Population \\
\hline Abaji & Abaji & 58,642 \\
Bwari & Bwari & 229,274 \\
Gwagwalada & Gwagwalada & 158,618 \\
Kuje & Kuje & 97,233 \\
Kwali & Kwali & 86,174 \\
Municipal & Abuja & 776,298 \\
Total & & $1,406,239$ \\
\hline
\end{tabular}

Source: National Population Commission (Census, 2006).

\section{Methodology}

This study relied on information arising from field auditing and evaluation of Abuja Master Plan. Conventionally the following critical issues provide the framework for evaluating and reviewing a Master Plan (Sumaila, 2004).

i. The philosophy and concepts embodied in the original plan.

ii. The goals, standards, and guidelines identified and the extent to which they were adhered to during plan implementation.

iii. The current reality of the city.

iv. The principles guiding the search for future planning action.

Drawing from these, our evaluation of Abuja Transportation Plan was based on the following:

i. Field assessment of the extent of implementation of the Plan.

ii. Field observation of distortions to and deviations from plan provisions.

iii. Existence of unauthorised/illegal transport infrastructure and operational activities in the territory.

The field checks involved visits to all the major traffic corridors in the city where we observed and documented information on the following:

a. Frequently congested arteries, intersections, and loading points.

b. Causes of the traffic bottlenecks such as street trading, lack of lay-byes, and absence of bus stops.

c. Presence or absence of the following:

i.Traffic Control facilities

ii. Parking facilities

iii. Side drains and other drainage facilities

iv. Road markings and road signs

v. Traffic signals and traffic light controls

vi. Pedestrian walkways 
d. Pattern of loading and unloading of passengers and goods.

e. Driver and pedestrian behaviours.

We also obtained information from published materials. Records of achievements of Federal Capital Development Authority (FCDA) contained in official documents were examined and used to provide empirical support for the study. We generated information on settlement growth and patterns in the FCT, functions and activities of the Transport Secretariat of FCDA and its operating departments, traffic mix and traffic flow figures on major arteries in the territory, information on mass transit activities in the territory for which Abuja Urban Mass Transit Company (AUMTCO) provided additional data. The information gathering exercise which was carried out intermittently within a period of six months (March-August, 2012) provided the needed data for characterizing the current transportation challenges confronting the Federal Capital Territory.

\section{Current and Emerging Transportation Challenges}

\subsection{Transport Infrastructure}

FCT has a fairly detailed and comprehensive Transportation Master Plan due perhaps to the earlier experience of Lagos. The objectives of the plan are to

i. Maximize public transport mobility for residents who do not own cars (Captive Riders).

ii. Provide high quality attractive transit services to hire those with cars (Choice Riders).

iii. Minimize traffic movement passing through the various development sectors.

iv. Provide multiple highway paths between development sectors thereby avoiding network bottlenecks.

v. Achieve maximum self-containment within the outlying sectors.

The strategies to be adopted are:

a) Buses mixed with other traffic on general routes.

b) Bus only on exclusive right of way.

c) Light Rail Transit (LRT).

d) Rapid Rail Transit (RRT).

In pursuance of these, a twelve - year, AbuTrans Initiative was prepared in 2005 to provide the following:

i. Expanded bus service in all areas.

ii. $286 \mathrm{~km}$ of light rail and commuter rail.

iii. $66 \mathrm{~km}$ of bus rapid transit service.

iv. 33,000 parking spaces at rail and bus stations.

v. 1000 high capacity buses for commuters within Abuja on public, private partnership initiative.

While efforts are currently on-going to meet these targets, field evidences suggest that in terms of grandiose design of structures and aesthetics, Abuja today seems to have met some of the goals of its creators. The city can be said to have a fairly good network of roads comprising Expressways, Arterials, Parkways and Collectors. But surprisingly most of these are concentrated on phase 1 which comprises only 95 out of the 208 districts of the FCT. Table 2 presents the level of road development in each of the four stages of development of Phase 1 .

Table 2. Stages of development of Phase 1 of Abuja City

\begin{tabular}{cccccc}
\hline Stages & $\begin{array}{c}\text { No of } \\
\text { Districts }\end{array}$ & $\begin{array}{c}\text { Planned period of } \\
\text { completion }\end{array}$ & $\begin{array}{c}\text { Lenght of Roads so far } \\
\text { constructed }\end{array}$ & $\begin{array}{c}\% \text { of Planned } \\
\text { Road Lenght }\end{array}$ & Remarks \\
\hline I & 10 & 1990 & $263.77 \mathrm{~km}$ & $90 \%$ & $\begin{array}{c}\text { With Fairly adequate } \\
\text { parking facilities }\end{array}$ \\
II & 20 & 1995 & $77.2 \mathrm{~km}$ & $35 \%$ & $\begin{array}{c}\text { Only in Wuye Jabi, utako } \\
\text { and Mabushi areas. } \\
\text { Only in Gwarinpa } 1 \text { \& II, } \\
\text { Kado, Lugbe. }\end{array}$ \\
III & 23 & 1998 & $53 \mathrm{~km}$ & $25 \%$ & $\begin{array}{c}\text { Ond } \\
\text { Essentially link roads to the } \\
\text { areas. }\end{array}$ \\
\hline
\end{tabular}

Source: FCDA documents, 2012. 
It is glaring from the Table that for over thirty years of the existence of the FCT, development has concentrated mostly on phase 1 area and the satellite towns, a situation which is now challenging mobility in the territory. The early relocation of the seat of government ahead of the proposed date changed the socio-economic data upon which traffic demand forecast in the plan was based relative to time and spatial distribution and thus diminishing the transportation system capacity to develop into an efficient flow (Sumaila, 2004).

Allied to this is the challenge of non- development of the public transit ways which link all the major activity centres, markets, offices and community halls. These transit ways would have gone a long way in solving the problems of transportation in phase 1 area by forming the core of Abuja's public transport system. Moreover, Abuja has reached the development level recommended for the introduction of Light Rail Transit and the Rapid Rail Transit. But surprisingly not even the bus only routes i.e. the Bus Rapid Transit (BRT) which is the true bus transit facility is yet to be introduced even as the threshold population and development levels have since been surpassed. This has exposed the lack of an integrated intermodal transport system for FCT as all movements in the territory today are road- based for which the existing road infrastructure is unable to cope with.

\subsection{Interchange Points/Bus Stations}

Central to operation of an integrated urban traffic system is the need for many passengers to change from one form of transit mode to another during the course of a journey. The conditions under which such acts of interchange take place are critical to the success and public acceptance of an integrated system. But in FCT, the construction of a Transportation Centre as provided for in the plan appears to have been abandoned and the site converted to other uses.

The result is that the two bus stops by Berger junction have become the unofficial transport interchange points. Buses from the satellite towns and inter-state commuter vehicles terminate their journeys at these points. At any given time of the day, the scene at these bus stops and the junctions by old FCDA Secretariat in Area 1 are direct replications of the chaos in Iddo Motor Park in Lagos. The sight is exactly what the Master plan seeks to avoid in the FCT. But pockets of such avoidable chaos are growing in Askoro/ Nyanya junction, Maitama junction, Zone IV bus stop and right in front of the new NTA building in Area Eleven. Thus, in the absence of public terminals, illegal private ones for inter-state buses and taxis now dot both commercial and residential districts in the city (see Figure 2).

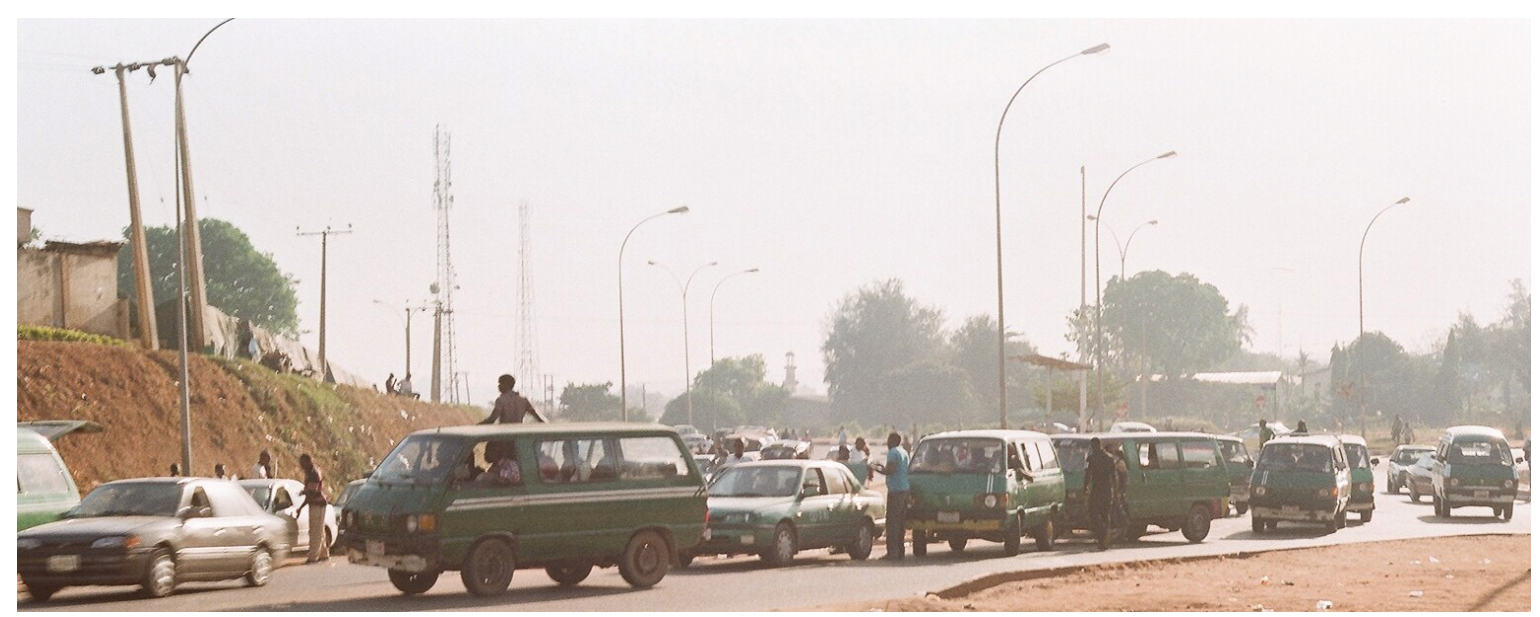

Figure 2. Illegal bus stop/ station at Area 1

\subsection{Parking}

Parking today is a major challenge in FCT. Though on - street parking facilities are provided on many routes in Abuja especially in the neighbourhoods, but increased car ownership has rendered them grossly inadequate. The parking problem is more acute on major arterials which provide access to centres of activities in the city. The expectation is that government offices, public buildings, hospitals, schools, shopping centres among others should provide within their premises either on, above, and below the ground parking facilities. But callers to such premises are usually denied parking thereby compelling them to park on the roads and made to pay for short- term durations. Unfortunately, off - street parking facilities are generally absent in most parts of the FCT. Thus, parking has today become a major obstruction to smooth flow of traffic in the entire capital territory. 


\subsection{Pedestrian Walkways}

For public transport to be an acceptable alternative to the private car in Abuja, good walkways have to be available. The plan estimated that about $15 \%$ of Abuja residents will have some disabilities which may give them reduced mobility. In addition, Tourists would normally be expected to walk unhindered from their hotels to the shops and CBD for shopping or seeing. Walkways are therefore required for this growing section of urban residents (FCDA, 1986).

Unfortunately, many roads in the FCT lack such facilities. Roads to Nicon Hilton, and Sheraton hotels, NNPC building, Ahmadu Bello Way have all lost sidewalk characteristics. In the CBD of Abuja, priority is given to vehicular traffic without consideration for sidewalk and provision of prams which can be used by nursing mothers. The bridges in Central Area have ramps without weave length while all the bridges linking Wuse to Central Area lack walkways as they disappear on approach to the bridges.

The greatest lack of imagination is seen in the construction of bridges and roads around the Stadium Complex which do not provide for walkways. This is strange since such a complex would generate the greatest level of non- vehicular traffic. Also the general provision of raised central medians around neighbourhood centres has created difficult access for pedestrians wishing to cross from one side of the street to the other. This is particularly serious in Garki I and II.

Churches and Mosques attract lots of visitors a high proportion of who are pedestrians. Worshippers are unable to walk from NNPC building, the Federal Secretariat and other structures to the mosque due to the absence of walkways. Similarly, it is observed that developers cut into the walkways in order to provide access to their properties especially in Asokoro District, Central Area and Eagle Square. All these increase vehicular traffic on the roads, and also aggravate the mobility problems of pedestrians and the physically challenged.

\subsection{Road Markings, Signs, and Traffic Signals}

These facilities are required in cites for the control, warning guidance and information of road users. They enhance traffic discipline, encourage full usage of available road space, and they add to the safety of traffic, besides improving traffic flow. These are absent in many areas of the city thereby contributing greatly to the traffic chaos experienced in the Capital territory. For traffic light controls, 85 junctions in the city have traffic lights controls, but about 25 more junctions require such facilities for effective coverage.

\subsection{Preponderance of Privately-Owned Low Occupancy Vehicles}

Most movements within the city and between the satellite towns are by private cars and taxis. Private vehicles are also used to meet the daily mobility needs of Abuja residents. Of the nearly 600,000 vehicles plying the roads of Abuja city daily, about 520, 000 are private. On Awolowo Road for instance, we observed a daily volume of 10,686 cars (both taxis and private) as against 155 big buses (High occupancy) and 4,166 Mini- buses.

Private ownership also characterises the provision of numerous mass transit vehicles used as public transport. These, known variously as 'Molue', 'Danfo' or 'Kabu- Kabu', are either previously abandoned scraps or mostly imported fairly used which quickly become old and rickety with tendencies to smoke or break-down frequently. These privately-owned vehicles constitute today the most significant, though largely unregulated means of public transport in most parts of Abuja metropolis. They are followed in importance by the use of motorcycles called (Okada) which were banned in the city a few years back when their nuisance value rose to an intolerable limit (see Figure 3). They unfortunately have been replaced by numerous Tricycles in the city, while in the satellite towns; motorcycle riders still recklessly ply all the roads without the least regard for road traffic regulation. They sometimes carry two passengers instead of one. Lives are being lost almost daily due to the lawlessness of motorcycle riders. All these are clear manifestations that Abuja lacks proper public transport support especially the use of high occupancy vehicles (HOVs) (Sumaila, 2004). 


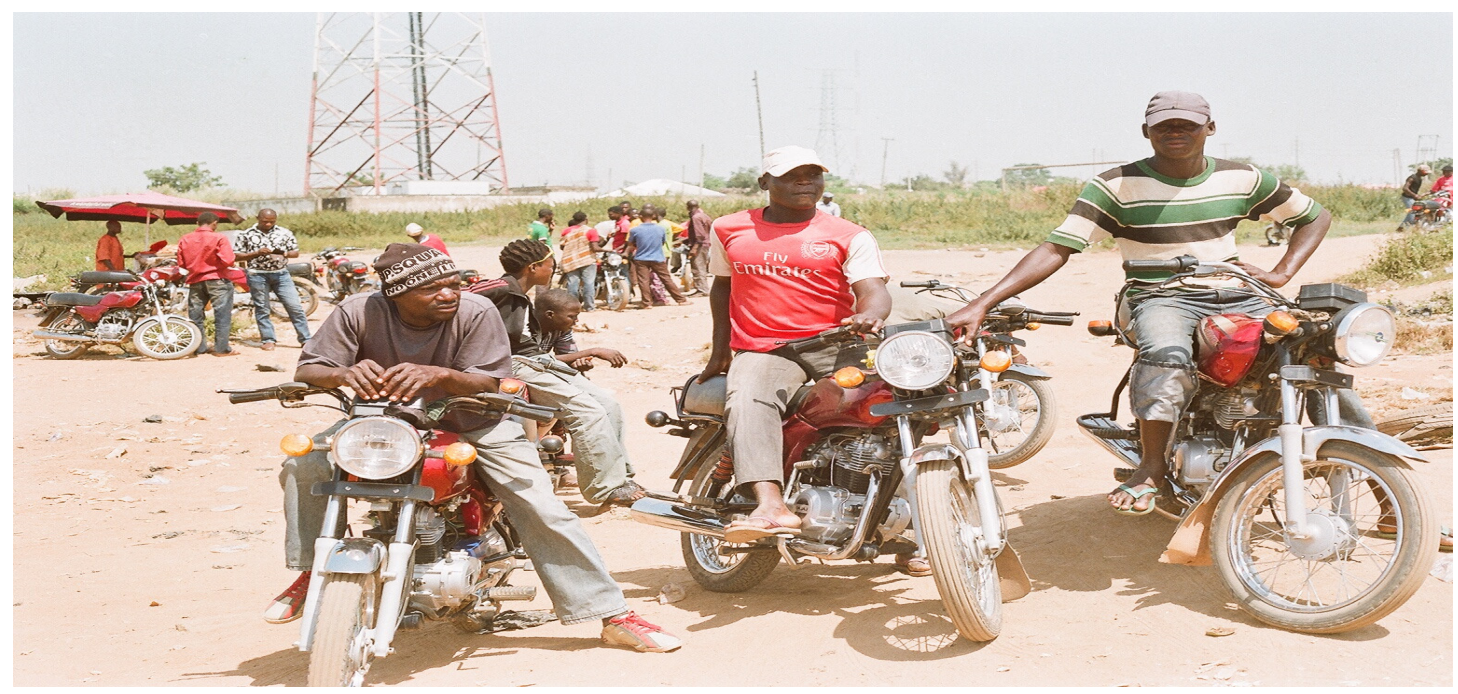

Figure 3. Motorcyclists waiting to pick passengers in the Satellite towns

Thus in summary, there is total absence of coordination and poor management of Abuja Urban transport system. These are reflected in heavy use of numerous mini- buses and taxis operated at the whims and caprices of the owners. They are highly unorganised plying any route without service standards. The situation is worsened by the Kabu-Kabu system and the numerous tricycles that dot the roads of FCT (see Figure 4).

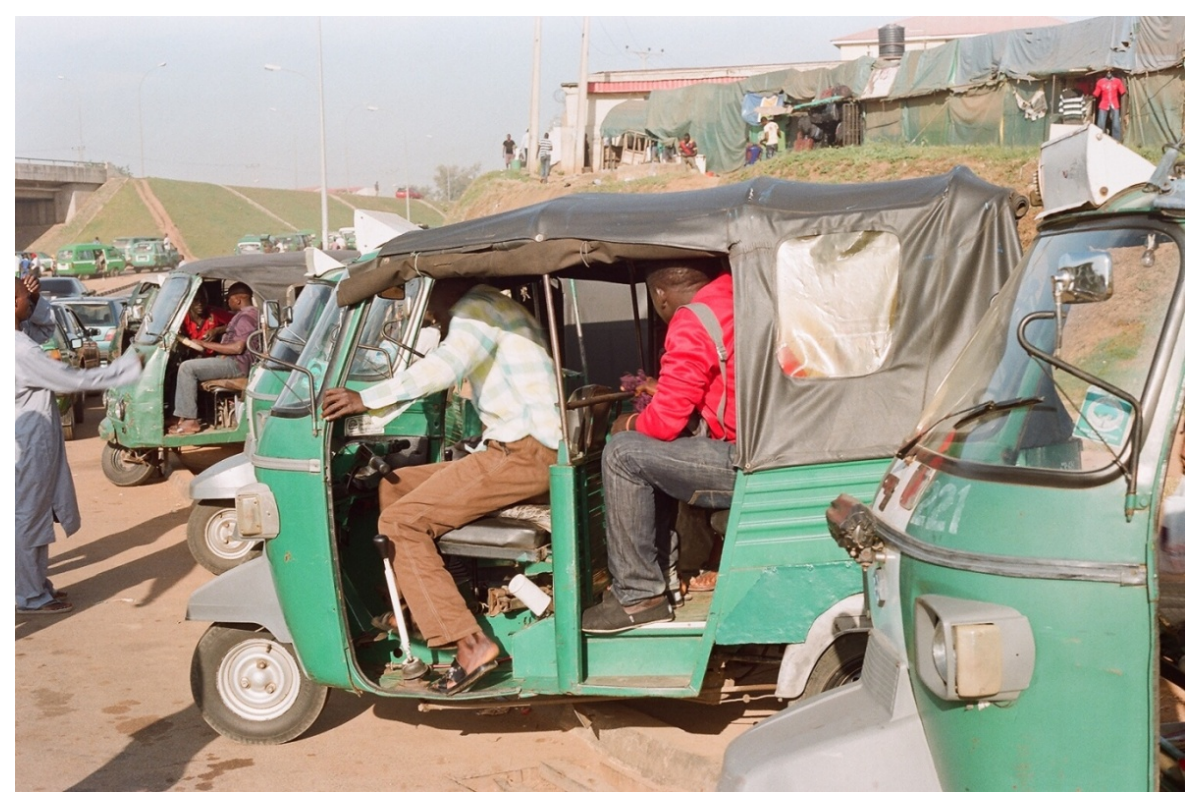

Figure 4. Tricycles used for public transportation

\subsection{Traffic Congestion}

One of the greatest challenges of transportation in the FCT is the considerable stress and strain now witnessed on the road system evident by prolonged traffic hold-ups. Traffic jams are now seen city- wide and are very serious especially at morning and evening peak hours. Passengers mostly school children, Government and private office workers wait endlessly daily at peak hours to catch vehicles to various destinations in the FCT. The critically congested areas are as shown in Table 3.

Generally, the congestion problem is most acute on the Expressways and major roads leading to the satellite towns especially during morning and evening peak periods. On roads to Kubwa, Nyanya, Airport and Gwagwlada, motorists and passengers are trapped for hours daily. The heavy vehicular traffic volumes recorded 
on the main roads and other arterials in the FCT can be used to further illustrate the congestion problem (see Table 4).

Table 3. Traffic congested areas in FCT

\begin{tabular}{|c|c|c|c|}
\hline & Congested points & Affected road links & Reasons \\
\hline 1 & Tipper Junction & Zuba road AYA and Berger Junctions & No bus stop/No Lay- byes \\
\hline 2 & Berger Junction & $\begin{array}{l}\text { Karmo Road, Central area, Area1, and } \\
\text { Tipper Garage Roads. }\end{array}$ & $\begin{array}{l}\text { No Lay-byes and bus stops except at } \\
\text { Central Area. }\end{array}$ \\
\hline 3 & Area 1. & $\begin{array}{l}\text { Nnamdi Azikiwe way, and roads to } \\
\text { Gwawalada, Nyanya, Central Area and } \\
\text { Berger Junction. }\end{array}$ & No lay-byes and bus stops. \\
\hline 4 & Apo Junction & $\begin{array}{l}\text { Central area, Apo District, Area } 1 \text { and } \\
\text { Nyanya Roads. }\end{array}$ & $\begin{array}{l}\text { No lay-byes/bus stops. Restricted } \\
\text { nature of intersections. }\end{array}$ \\
\hline 5 & AYA Junction & Central Area and Nyanya roads & $\begin{array}{l}\text { No lay-byes/bus stops and high traffic } \\
\text { generation from Karmo and Nyanya. }\end{array}$ \\
\hline 6 & $\begin{array}{l}\text { Federal Secretariat } \\
\text { and Central Areas. }\end{array}$ & $\begin{array}{l}\text { Connecting Roads and Roads to the } \\
\text { Satellite towns. }\end{array}$ & $\begin{array}{l}\text { Heavy traffic generation in satellite } \\
\text { towns mostly Gwagwalada, Karu,and } \\
\text { Nyanya }\end{array}$ \\
\hline
\end{tabular}

Source: Field Survey, 2012.

Table 4. Average Daily Traffic Volumes on Selected Routes

\begin{tabular}{lc}
\hline Route & Average Daily Traffic Volumes \\
\hline Shehu Shagari Way & 23,523 \\
Ahmadu Bello Way & 52,121 \\
Moshood Abiola Way & 28,012 \\
Tafawa Belewa Way & 32,755 \\
Herbert Macaulay Way. & 42,585 \\
Awolowo Way & 41,916 \\
Muhammadu Buhari Way. & 23,409 \\
Nnamdi Azikwe Way & 27,588 \\
Nyanya Road & 86,147 \\
Airport Road & 87,326 \\
Kubwa Road & 96,425 \\
\hline
\end{tabular}

Source: FCDA Documents, 2012.

The situation is aggravated by emerging development in the capital territory. The Master Plan provides that school traffic should be pedestrian - based, but the reality of today is that parents send their children to schools away from their neighbourhoods. The implication is that vehicles take them to and from school daily thereby generating two trips per day per family. When aggregated, the quantum of trips generated is enormous and this contributes greatly to the congestion problem.

Allied to the above is that some markets are located within the city without access considerations. The Wuse market typifies this. Traffic generated by the market causes severe traffic jams and inconvenience along all adjacent roads, adjoining linkages and intersections. As a result, motorists park unlawfully on the street right-of-way and access the parkways at random. This situation has caused great damages to the road perimeters and facilities. The hold-ups generated have created conducive operating environments for criminals who snatch personal effects of unsuspecting pedestrians and motorists. 
In the same way, markets have developed on the major roads linking the satellite towns thereby causing daily obstructions to traffic. Similarly the Central Mosque and the CAN church have blocked major roads (B8, B4, and B14) thus obstructing traffic circulation along these important roads thereby aggravating the congestion situation.

Vehicles are also abandoned at will on the access roads linking residential areas within Wuse 1 and Garki 1 as well as along the local distributor roads linking each zone within the districts. Lay- byes on the distributor roads have been converted to loading points, obstructing through- traffic. Most of the "Green Areas" in the Master Plan are lacking access roads and have been occupied by buildings. Others are illegally used as recreation areas thereby serving as traffic generating points. The impact of this local traffic on the adjoining areas is adverse since transport is a system and hindrance at any site ripples throughout the network (see Figure 5).

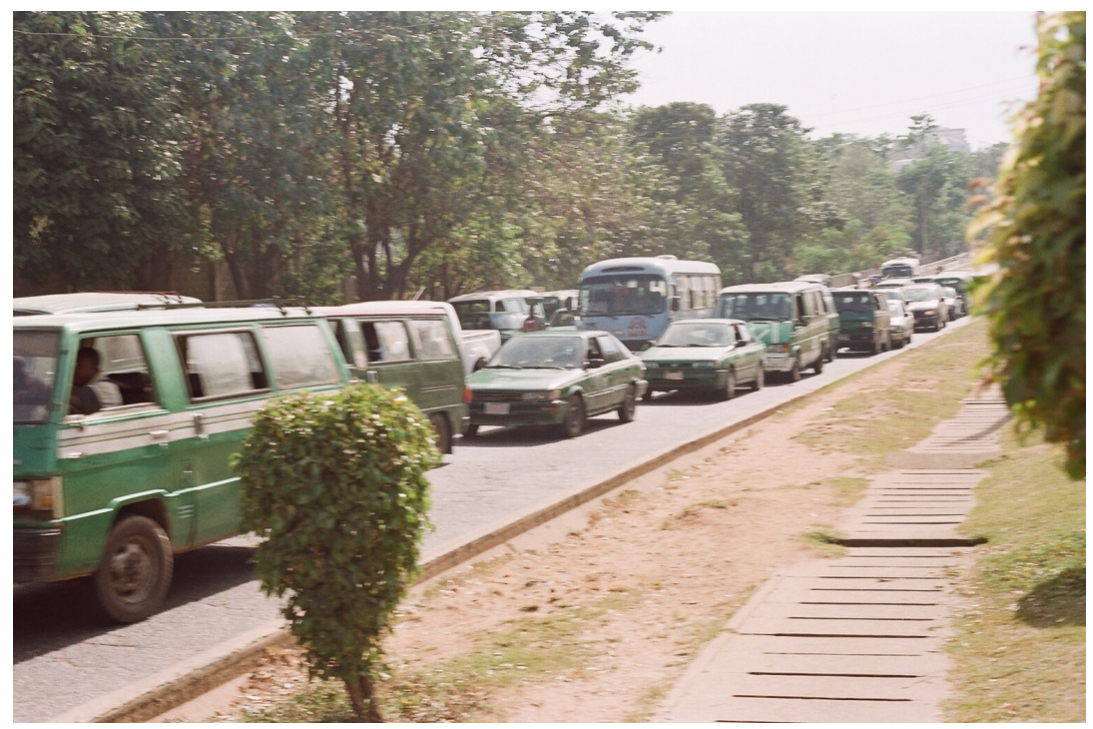

Figure 5. A typical congested road in Garki Abuja

\subsection{Mass Transit}

In FCT today, public transportation is an all- comers' game creating conflicts in operation and differences in service quality. This confusion prompted government's direct involvement in the provision of public transit services through the establishment of Abuja Urban Mass Transit Company (AUMTCO) in 1989. In 2005, FCT delineated the city into three operational zones and granted licenses to three operators namely.

i. MUTL responsible for the northern zone expected to operate with 61 Mercedes Comic buses with capacity of 80- passengers.

ii. Sonic Global Recourses for central zone to operate with 230 buses.

iii. -Sigwal/AUMTCO for the southern zone, with Sigwal providing 150 buses and AUMTCO 60 buses (Chigboh, 2006).

These targets have not been met because the agreement was neither properly consummated nor the concession enforced resulting in free- market access to all comers. The other two operators have so far been unable to adequately service the assigned routes, and AUMTCO is now filling the gap on those routes- Gwagwalada and Kubwa. But AUMTCO is incapacitated due to the following:

1) FCT Administration controls fares charged based on public service principle. With the cost of diesel $100 \%$ higher than petrol, the company's fares are less than half of those charged by the unregulated mini - bus operators.

2) No corresponding subsidies so as to bridge the gap as is the practice in developed economies.

3) Striking a balance between public service provision and breaking - even is the sad paradox of the company's operation. 
4) Manages a large fleet size of 191 buses boosted by additional 200 buses arising from Subsidy Re-Investment Programme (SURE-P). The Company is therefore burdened by large number of staff.

5) Faces a maintenance problem as only 31 out of the existing fleet of 95 are currently serviceable.

\subsection{Satellite Settlements and Development of Squatter and Shanty Settlements}

Abuja today has become a big and sprawling city with population significantly exceeding projected forecast. The design of the city either intentionally or inadvertently conforms to the concept of the "GARDEN CITY of TOMORROW" But it is surrounded by satellite towns and suburbs which harbour a mixture of people most of who belong to the low income group who commute daily with the centre. Thus, since its creation about thirty years ago, the city has remained the destination of mass movement of people from different parts of the country thereby increasing the population of the main city and its adjoining settlements even to the point of near explosion.

Within the capital city are nine (9) of the nineteen (19) large communities in the FCT. These are Zuba, Kubwa, Jiwa, Idu, Life camp, Karmo, Garki, Nyanya and Karu. These towns today account for about half of the total population and about $70 \%$ of the urban population of FCT. There are also minor concentrations such as the Gwagwalada-Kinaka-Kiye triangle in the centre of FCT, and the Ashaa - Rubochi-Abaji Triangle in the South-West corner. Only three of the largest settlements are outside these concentrations namely Bwari in the North, Dobi in the Northwest and Karshi in the East. The bulk of these large human populations commute daily with Abuja city thereby worsening the traffic congestion problem. Coming from these Satellite settlements in the morning and making return trips in the evenings have become harrowing daily experiences.

Allied to the above is the fact that no provision is made in the plan for low income earners. This has led to the emergence and development of squatter and shanty settlements in different parts of the capital territory. The problem started in 1999 when displaced settlements meant to be resettled outside the FCT were inadvertently resettled at various locations within the territory, thereby altering the entire population equation and thus exerting serious pressure on the limited transport infrastructures. Since then the fringes of such settlements have been increasing and expanding while their number has multiplied in different parts of the territory.

Thus, despite its wealth, Abuja today harbours many of Nigeria's most deprived communities suffering and staggering under the heavy burden of transportation poverty and exhibiting the worst symptoms of immobility. All these have complicated mobility demands and challenged accessibility in the last few years.

\subsection{Safety Challenge}

Though standard roads have been constructed in Abuja, proper management of the facilities especially with regard to setting standards for drivers and their vehicles is inadequate. Part of the problem relates to the infiltration of residences into business zones and vice versa. It is common to find high industries and workshops in Garki and Wuse residential quarters. Pedestrian walkways have been taken over by beggars and hawkers creating conflicts between demands for access and movement. Of importance is the development of squatter and shanty settlements around industrial areas and along busy primary distribution roads such as Airport road, Karmo and Kubwa roads. These have influenced haphazard development at the fringe towns of FCT such as Mararaba and Zuba. The safety implication of this development is enormous. Settlers have often encroached right up to the edge of the roads creating hazardous conditions for pedestrians and vehicular traffic.

\subsection{Administrative Challenge}

Presently in FCT, the Transport Secretariat handles policy matters relating to transport. It is led by the Transportation Secretary who operates through three departments namely: Transportation (Rail Development); Public Transportation; and Road Traffic Services all headed by Directors. As part of its achievement, the Secretariat has produced a draft Transport Policy for FCT. Since FCDA is responsible for infrastructural development one is not too sure of the level of input of the Transport Secretariat to Abuja transport infrastructural development. .Designs and construction have been left in the hands of Expatriate Contractors, supervised by Civil Engineers who may lack professional knowledge needed for urban transport development. The apparent lack of a centralised authority for management of transportation in the territory has diminished capacity for planning and coordination. This results in grossly ineffective traffic law enforcement permitting operators and other road users to behave the way they like. Available transport infrastructural capacities are suboptimally utilized allowing current usage to impact so negatively on the environment while the operation of vehicles on the roads is virtually in the hands of nobody. 


\section{Recommendations and Conclusion}

It can safely be concluded that the transport challenges in FCT today are multi-dimensional. Tackling them appropriately would require the application of multiple modes (Mulitmodalism) which in turn would generate multiple agencies, multiple jurisdictions and multiple disciplines. It is by integrating these multiple dimensions that a sustainable transportation management system can be instituted.

But perhaps the best approach to facilitate the attainment of the goals of integration and of effective and efficient mobility is through a central authority with functional independence to exclusively handle transport matters. This is because in cities of developing countries as is the case with Abuja, institutions are often ill-equipped to deal with the share increase in traffic or to adopt advanced technology that would help them overcome traffic problems. It is rare to find a single agency with the comprehensive authority it needs to deal with the large range of transport problems and coordinate overall solutions. Instead, authorities are usually divided along several agencies, each dealing with different elements of the transportation problem, while their authority boundaries often tend to be indistinct resulting in duplication of responsibilities.

We have shown in this paper that the Abuja case is not an exception. Significant government funding has been injected into the transport system through FCDA, Transport Secretariat and AUMTCO among others. Unfortunately the huge spending has not yielded the desired results as the agencies are working at cross-purposes thereby creating confusion and conflicts in the transport system. Moreover, the level of development of the city now demands greater private sector participation and investment in infrastructural provision and service delivery. But the bureaucracy and suspicion which the present institutional mechanism generates have tended to discourage this partnership.

The foregoing therefore makes the need for institutional reorganization very potent. This is based on the principle of separation of policy- making from operation and regulation as is the case with the Telecom sector in Nigeria. Based on this premise, the creation of Abuja Area Transportation Authority (AATA) is therefore recommended to handle transport matters in the FCT. This would involve the following:

i. Redefine the functions of Transport Secretariat to become responsible for policy development and oversight.

ii. Transfer of planning, implementation, investment, regulatory and enforcement functions from Transport Secretariat to the Authority.

iii. Transfer of engineering function of FCDA to the Authority.

Consequently, the Authority will perform the following functions

1) Transport Infrastructure development involving planning, design and construction of roads, rail and Public Transport Infrastructure.

2) Planning, funding and contracting of public transport services.

3) Economic Regulation comprising licensing, tariff regulation, standard setting and licensing of ancillary service providers.

4) Safety Regulation and Traffic Management focussing on traffic laws and regulation, speed regulation, vehicle load control, and central control systems.

5) Research and Data Management.

6) Coordination, promotion and consultations.

The Authority would function as an autonomous and self - accounting organ of Government receiving direct funding from various licensing fees, leasing and concession fees, and fines among others.

It is hoped that the implementation of this recommendation would strengthen the capacity of FCDA to plan, manage and regulate urban transport and serve as the sustainable transportation management strategy for FCT.

\section{Acknowledgements}

The Author acknowledges the support of the Transport Secretariat of FCDA especially the Director, Public Transportation who assisted in the data gathering exercise. The technical support of MicroMab and Linkage Consulting Services and the assistance of Tinuke Sumaila are equally appreciated. 


\section{References}

Chigboh, C. N. (2006). Abuja Transport System Memorandum Presented by Transportation Secretariat of FCDA to National Council on Transport. Held in Kano, 4-6 $6^{\text {th }}$ June, 2006.

Federal Capital Development Authority. (1986). The Making of a New Capital City for Nigeria. FCDA Official Document.

Gbujie, P. O. (2003). Evaluation of Implementation of Abuja Master Plan. A case study of Road Transport Infrastructure Unpublished MSC Thesis, School of Professional Studies, Nigerian Institute of Transport Technology (NITT) Zaria.

International Planning Associates. (1979). The Master Plan for Abuja the New Federal Capital of Nigeria.

Ogunsanya, A. A. (1995). The Future of Transportation in Nigeria. $15^{\text {th }}$ Anniversary Lecture of ANAMMCO, Enugu.

Sumaila, A. G. (2004). Road Transportation in Abuja. Paper Presented at a One-Day Seminar on Road Transportation in Urban Centres of Nigeria: A Case Study of Abuja, Organized by National Economic Intelligence Committee, Abuja, $18^{\text {th }}$ Febuary.

Sumaila, A. G. (2009). Urban Public Transportation, Institutional and Legal Framework; Issues Options and Challenges. Paper presented at an International Conference on Public Transportation, Organized by Transport Secretariat, FCT, Abuja.

Sumaila, A. G. (2012). Sustainable Transportation Management for Federal Capital Territory, (FCT). Paper Presented at a One-Day Retreat for Staff of FCT Transportation Secretariat, Abuja. ${ }^{\text {th }}$ August, 2012. 